\title{
UNDERSTANDING SPATIAL VARIABILITY OF CROPPING SYSTEM RESPONSE TO CLIMATE CHANGE IN PUNJAB STATE OF INDIA USING REMOTE SENSING DATA AND SIMULATION MODEL
}

\author{
Rojalin Tripathy ${ }^{\mathrm{a}^{*}}$, Shibendu S. Ray ${ }^{\mathrm{a} 1}$, Harsimran Kaur ${ }^{\mathrm{b}}$, S. K. Jalota ${ }^{\mathrm{b}}$, S. K. Bal ${ }^{\mathrm{b}}$ and Sushma Panigrahy ${ }^{\mathrm{a}}$ \\ ${ }^{a}$ Agriculture, Terrestrial Biosphere \& Hydrology Group, EPSA, Space Applications Centre, Ahmedabad, India \\ ${ }^{\mathrm{b}}$ Punjab Agricultural University, Ludhiana, Punjab, India \\ *Email:rose_t@sac.isro.gov.in \\ ${ }^{1}$ Commission VIII, WG VIII/6
}

KEY WORDS: CropSyst, Spatial impact, HadCM3, A2, B2, Agricultural system yield

\begin{abstract}
:
The present study investigated the impact of climate change, as projected by the Global Climate Model, HadCM3 for two different storyline (A2, B2), on the total crop production of Punjab state of India and its spatial variability for three future periods (2020, 2050 and 2080). Gridded weather data ( $1 * 1$ degree) from India Meteorological Department was used as baseline weather. Daily future weather data were generated from baseline and projected change for each weather parameter (maximum and minimum temperature, rain fall). Both baseline and future weather data were then interpolated to $25 * 25 \mathrm{~km}$ grid level. The cropping system model, CropSyst was used for simulating the climate change impact on crop productivity. Cropping system map generated from remote sensing data for Punjab was used for finding the major cropping systems in each of the $25 \mathrm{~km}$ grid. Using this information cropping system productivity in each grid was estimated for baseline weather as well as for projected weather. Spatial pattern was generated for the difference in grid yield for each scenario. Results showed yield decline in all cropping systems except for few grids during 2020 in B2 scenario. Aggregated district yield indicated that for A2 scenario, in the near future (2020) Roopnagar (in eastern Punjab) will be the most affected district with around $35 \%$ reduction in cropping system yield where as Hoshiarpur (in north-eastern part) will be most affected during 2050 and 2080 . For B2 scenario, Hoshiarpur was found to be the most vulnerable region for all the three periods.
\end{abstract}

\section{INTRODUCTION}

Climate variability and climate change - can have strong impacts on crop production and therefore, has a direct impact on food security. Detailed scientific understanding of the magnitude and rate of climate change impacts on crop productivity is necessary for assessing the impacts on national economy. Such impacts have recently been analyzed using process-based crop models to predict crop yields under both current and future climate conditions (Wassenaar et al., 1999, Tubiello et al., 2000, Donatelli et al., 2002). The crop models used in these studies were designed to run for individual crops at different locations. However, quantification of impact of climate change on the productivity of different cropping systems at spatial scale is required for visualizing the impact on the total crop productivity of a region. This has led to the coupling of crop growth simulation model and spatial techniques that deal with the variability in soil, cropping system, management practice and climate of the region of interest. Spatial variation of crop yield response to climate change was studied by Thornton et al. (2009) for East Africa. However, in Indian context study of climate change impact on crop productivity at spatial scale is very few. Hence, the present study was carried out with an objective of investigating the impact of climate change projected by the Global Climate Model, HadCM3 for two different storyline (A2, B2) on the total cropping system productivity of Punjab and its spatial variability for three future period (2020, 2050 and 2080). The SRES team defined four narrative storylines, labelled A1, A2, B1 and B2, describing the relationships between the forces driving greenhouse gas and aerosol emissions (Figure 1). Each storyline represents different demographic, social, economic, technological, and environmental developments that diverge in increasingly irreversible ways.



Figure 1. The four IPCC SRES scenario storylines (source: Nakicenovic et al., 2000)

In simple terms, the four storylines combine two sets of divergent tendencies: one set varying between strong economic values and strong environmental values, the other set between increasing globalization and increasing regionalization (Figure 1). Here we have chosen two regional storyline (one with strong economic development and the other with strong environmental development) to understand the impact under these two extreme situation.

For this investigation the cropping system model CropSyst (Stockle, et al., 1994) which has been modified for simulating the crop growth under varying levels of $\mathrm{CO}_{2}$ was used. 


\section{MATERIALS AND METHOD}

\subsection{Study Area}

The study was carried out for Punjab state of India. It lies between $73^{\circ} 53^{\prime}$ to $76^{\circ} 55^{\prime} \mathrm{E}$ longitude and $29^{\circ} 33^{\prime}$ to $32^{\circ} 31^{\prime} \mathrm{N}$ latitude with the elevation ranging from 175 to $300 \mathrm{~m}$ above mean sea level. The climate of the study area is semiarid. Most of the soils of Punjab, which are a part of Indus plains and derived from alluvium, are deep. The soil texture varies from sand to silty clay, having low to medium in organic matter contents. It comprises three major cropping systems of India, viz. Rice-Wheat, CottonWheat and Maize-Wheat.

\subsection{Spatial Technique}

Whole of the Punjab was divided into a number of square size grids $(25 \times 25 \mathrm{~km})$. Weather data and cropping system type was generated at this grid level. Punjab constitutes of 109 grids of $25 \times 25 \mathrm{~km}$ size. Yield simulation was carried out at this grid level after linking the CropSyst application module to the input files of each grid.

\subsection{Climate data and Future weather generation at grid level}

2.3.1 Baseline data: Daily Gridded weather data (1x1 degree) from India Meteorological Department for past 30 years (19712000) was averaged and used as base line weather. A modified version of the Shepard's angular distance weighting algorithm has been used for interpolating the station temperature data into $1^{0} \mathrm{Lat}$ $\mathrm{x} 1^{0}$ Long grids (Srivastava et al., 2008). Total number of grids in India is $1120(35 * 32)$.

2.3.2 Climate change data: Monthly change in three important weather parameters for crop growth (maximum and minimum temperature, rainfall) was taken from the Global Climate Model UKMO, HadCM3 (United Kingdom Meteorological Office, Hadley Climate Prediction Centre Model, Mitchell et al., 1998). The change is against a baseline weather data, that is the average of 30 years historical weather data (from 1961-1991). The spatial resolution of the GCM data is $3.75^{0} \times 2.5^{0}$ and the data format is Excel data inter change format (DIF). The original global data was converted to image form using ENVI software and was resized according to the baseline data boundary. The spatial resolution was made to $1 \mathrm{x} 1$ degree using the cubic convulsion option to match the spatial resolution of baseline weather. Hence, even the state of Punjab was less than the grid size of GCM, by interpolation using neighbouring grids four grid cells could be generated for the state. This is the standard procedure for impact assessment using GCM (Carter, 2007).

Daily parameter change data files were generated assuming same change in each day of a particular month. The rainfall data was converted to $\mathrm{mm}$ per day from $\mathrm{kg}$ per ha in the original file. The daily files for the change in future Tmax, Tmin and rainfall was generated for two scenarios and three different future periods. Within each scenario, future Tmax, Tmin and rainfall at $1 \times 1 \mathrm{~km}$ grid were generated using the baseline weather from IMD data and daily future change from the HadCM3 model. The spatial variability in future weather was observed at the resolution of baseline data. The three data files were interpolated to $25 \times 25 \mathrm{~km}$ grid level using the Thin Plate Spline interpolation technique and converted to one single file. Grid wise weather file in the CropSyst format was generated using a FORTRAN program.

\subsection{Cropping System Map}

The cropping system map of Punjab state was derived using multi-date remote sensing (SPOT-VGT) data and a hierarchical classification approach (Panigrahy et al., 2010). SPOT-VGT data has a spatial resolution of $1 \times 1 \mathrm{~km}$. The cropping system map at $1 \times 1 \mathrm{~km}$ resolution is given in figure 2. It shows that, Punjab state has three major cropping systems, i.e. Rice-Wheat, Cotton-Wheat and Maize-Wheat. The cropping system class $(1 \times 1 \mathrm{~km})$ with highest frequency in a $25 \mathrm{~km}$ grid was taken as the cropping system of that grid.

\subsection{Crop Coefficients for CropSyst Model}

Soil data and calibrated crop coefficients of the five individual crop cultivars (Rice: PR111, Wheat: PBW343 and PBW373, Maize: KH528 and Cotton: H1098 was collected from field experiments conducted at Punjab Agricultural University Farms (Jalota et al., 2008, 2009, 2010). Wheat Variety PBW373 was used for cotton-wheat system and PBW 343 was used for other two systems. Normal sowing date as recommended by the state agricultural department for each crop in the respective systems was taken as the planting date for current and future yield simulation. For Rice-Wheat system 20 June was used as the planting date for rice and 15 November was taken as the planting date of wheat. For Cotton-Wheat system the planting date used for cotton was 15 May and that for wheat was 5 December. For Maize-Wheat system the planting date used for maize was $15 \mathrm{Jy}$ and that for wheat was 20 November.

\subsection{Yield simulation and Impact assessment}

2.6.1 CropSyst model: CropSyst calculates dry matter accumulation as a function of daily intercepted solar radiation and daily crop transpiration using constant coefficients of radiation use efficiency (RUE) and transpiration efficiency (K). The original model equations were modified for accounting the effect of elevated $\mathrm{CO}_{2}$ (Tubiello et al., 2000). Different coefficients were used to increase daily crop RUE as a function of $\mathrm{CO}_{2}$ level for $\mathrm{C} 3$ (Rice, wheat and cotton) and $\mathrm{C} 4$ (maize) crops. This value is for a doubling of atmospheric $\mathrm{CO}_{2}$ from 350 to $700 \mathrm{ppm}$, the increase in potential crop growth was $25 \%$ for $\mathrm{C} 3$ and $10 \%$ for $\mathrm{C} 4$ crops. In the present study $\mathrm{CO}_{2}$ concentration was taken as $380 \mathrm{ppm}$ for current, $420 \mathrm{ppm}$ for $2020,480 \mathrm{ppm}$ for 2050 and $540 \mathrm{ppm}$ for 2080 period. Accordingly for a present level of $\mathrm{CO}_{2}$ $(380 \mathrm{ppm})$ and elevated level of $\mathrm{CO}_{2}(420,480$ and $540 \mathrm{ppm})$ the fraction of increase in $\mathrm{C} 3$ and $\mathrm{C} 4$ crops were calculated and used in the crop file of the respective crops and years.

Simulation was done for each cropping system under non stressed $\mathrm{N}$ and normal irrigation practice followed in the respective cropping system. Cropping system map generated from remote sensing data for Punjab was used for finding the major cropping system in each of the $25 \mathrm{~km}$ grid. Using this information cropping system yield in each grid was estimated for base line weather as well as for projected weather for three period and two scenarios. 
The difference in cropping system yield was then estimated at grid level and map was generated for the difference in grid yield during the three projected period for each scenario. The differences are averaged at district level after overlaying the district boundary. The boundary grid of two districts was included in the district where more than $50 \%$ of that grid falls. The methodology followed is schematically depicted in figure 3 .

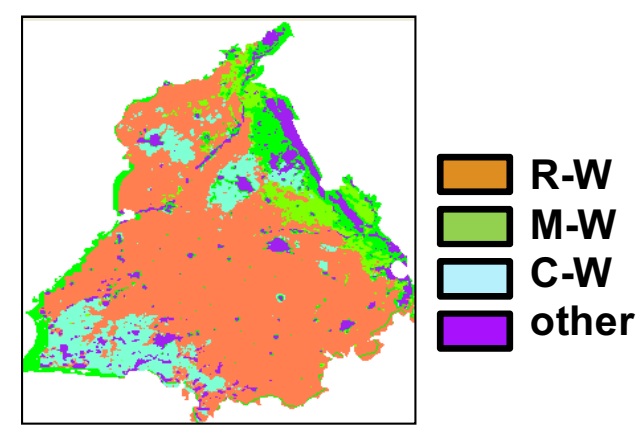

Figure 2: Cropping system map of Punjab (Source: Panigrahy et al., 2010)

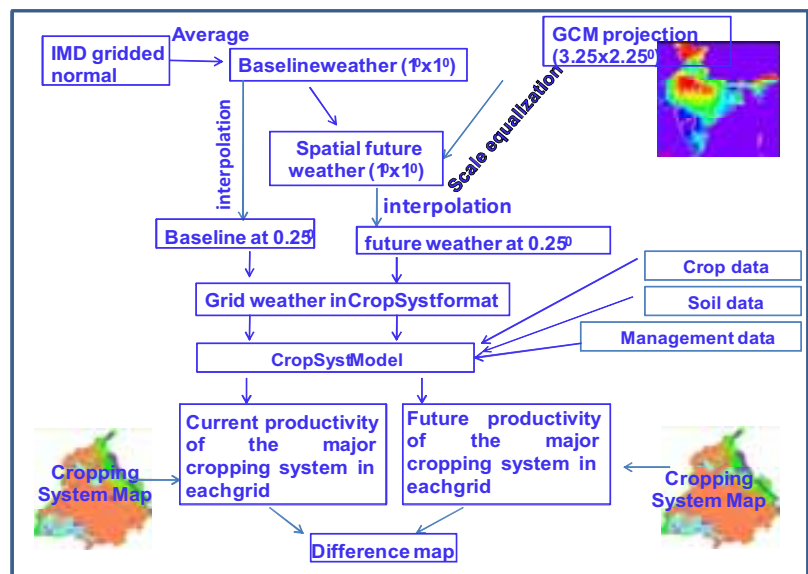

Figure 3. Schematic representation of the methodology followed for impact assessment

\section{RESULTS AND DISCUSSION}

Result showed yield decline in all cropping systems except for Maize-Wheat in which the yield increased in few grids during 2020 in B2 scenarios. As expected under A2 scenario, the reduction in grid yield varied from 2 to $54 \%$ in $2020,19-58 \%$ in 2050 and $41-80 \%$ in 2080, while in B2 the respective reductions were $-7.3-39 \%$ ('- ' indicate higher as compared to current), 20-57 $\%$ and $24-61 \%$ (Figure 4). Mall et al., 2004 had shown that there was a decrease (ranging between about 10 and $20 \%$ ) in soybean yield in three different future scenarios when the effect of rise in surface air temperature at the time of the doubling of $\mathrm{CO}_{2}$ concentration was considered. Krishnan et al., 2007, using 3 GCMs and 2 crop models, found the yield reduction of rice crop between 7-26\% for 4 degree temperature rise and different $\mathrm{CO}_{2}$ concentrations. Aggarwal et al., 2010 found that in Western UP in 2080 period, the yield reduction in rice was $2.91 \%$ to $14.68 \%$ in A2 scenario, and 0.90 to $7.53 \%$ in B2 scenario. Similarly, for wheat the reduction ranged from $-0.21 \%$ to $16.73 \%$ in $\mathrm{A} 2$ and $15.56 \%$ to $3.09 \%$ in B2 scenario. The yield reduction values are high in our case because, in our study, the cropping system productivity has been considered. So the reduction is not of single crop but of two crops, in the system.

Aggregated district yield indicated that for A2 scenario, in the near future (2020) Roopnagar (in eastern Punjab) will be the most affected district with around $35 \%$ reduction cropping system yield where as Hoshiarpur (in north-eastern part) will be most affected during 2050 and 2080 under present day management situation (Table 1). For B2 scenario, Hoshiarpur was found to be the most vulnerable region for all the three period with a reduction in cropping system yield of around 25 and 48 per cent during 2020 and 2080, respectively, if same cropping system will be followed with similar management practices.

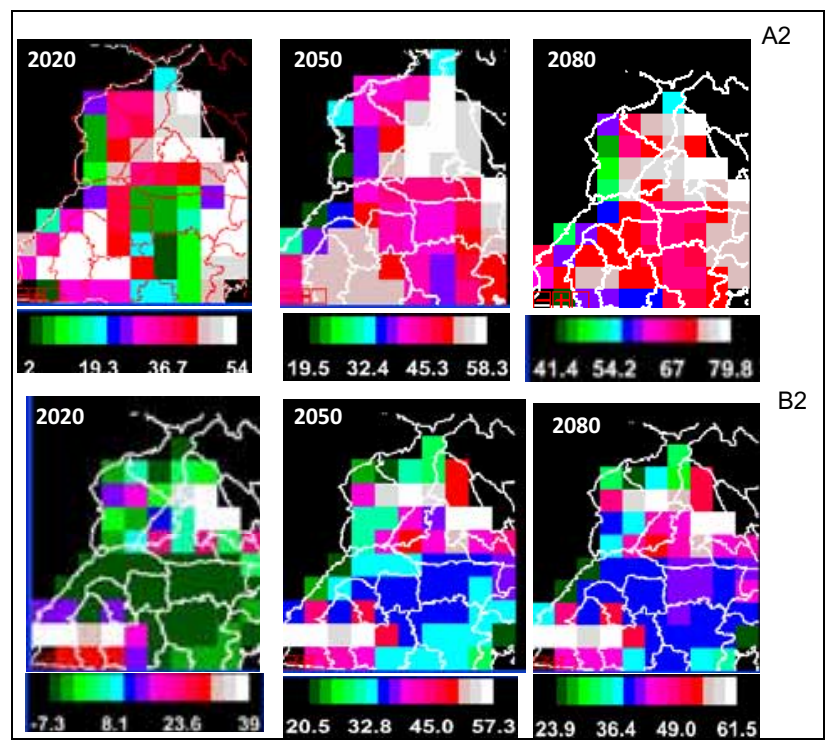

Figure 4: Reduction in cropping system yield in Punjab under A2 and $\mathrm{B} 2$ scenarios

\begin{tabular}{|l|ccc|ccc|}
\hline \multirow{2}{*}{ Dist } & \multicolumn{3}{|c|}{ A2 } & \multicolumn{3}{c|}{ B2 } \\
\cline { 2 - 7 } & 2020 & 2050 & 2080 & 2020 & 2050 & 2080 \\
\hline Amritsar & 20.08 & 33.41 & 46.47 & 14.26 & 30.66 & 36.52 \\
Bhatinda & 30.55 & 31.46 & 51.91 & 16.16 & 35.62 & 37.64 \\
Faridkot & 30.28 & 31.22 & 53.18 & 10.72 & 32.39 & 34.18 \\
Firozpur & 32.41 & 35.23 & 58.70 & 23.25 & 39.22 & 40.84 \\
Gurudaspur & 21.65 & 29.16 & 50.19 & 5.78 & 20.56 & 24.73 \\
Hoshiarpur & 33.50 & 37.93 & 62.13 & 24.58 & 48.71 & 48.17 \\
Jalandhar & 29.85 & 36.09 & 56.26 & 13.66 & 40.84 & 42.61 \\
Kapurthala & 23.76 & 28.79 & 51.54 & 4.21 & 23.56 & 27.02 \\
Ludhiana & 6.58 & 25.29 & 44.35 & 1.71 & 27.77 & 30.37 \\
Patiala & 29.49 & 31.20 & 53.74 & 3.59 & 25.11 & 28.74 \\
Rupnagar & 34.59 & 37.86 & 59.04 & 18.60 & 45.08 & 46.32 \\
Sangrur & 3.08 & 22.63 & 43.99 & 2.39 & 26.53 & 29.51 \\
\hline
\end{tabular}

Table 1. District-wise reduction in cropping system yield under different climate change scenarios 
However, all these yield change computed in this study would have large amount uncertainty associated with this. There is uncertainty in the magnitude of climate change and its spatial and temporal distribution. For these reasons, GCMs results must be considered as representative of physically plausible future climates, rather than exact predictions (Tubiello \& Ewert 2002). Similarly the uncertainties could also be due to the impact assessment models. The crop models have been calibrated with current weather. Hence, the relationship of $\mathrm{CO}_{2}$ and Temperature with yield may change in the climate change scenario (Aggrawal \& Mall, 2002; Mall et al., 2004), thereby making the predictions more uncertain. Added to that, the adaptation strategies such as change in variety and altered agronomy can offset the impacts of climate change (Naresh Kumar et al., 2011). Also the natural adaptation capacity of any cultivar to the change can not be accounted for in the simulated results. So these studies provide an indication of significant change in yield and the exact values may not be possible. However, as Lobell et al. (2006) mentioned, despite uncertainties in emission scenarios, climate responses, and crop behaviour, the unambiguous effect of warming from climate change will be to reduce yields.

\section{CONCLUSIONS}

This study aimed at investigation of climate change impact on total crop production of Punjab at spatial scale. Thus there are two major contribution of this study, i) assessing the impact on cropping system yield and not of single crops, which majority of current studies consider; and ii) providing a spatial variability of climate change impact. The results clearly discriminated zones with the different levels of possible impact. Though the exact values of yield change may have large uncertainty associated, this information may be of great use while deciding the priority area for mitigation and adaptation measures.

\section{REFERENCES}

Aggarwal, P. K., Naresh Kumar, S., Pathak, H., 2010. Impacts of climate change on growth and yield of rice and wheat in the Upper Ganga Basin. WWF-India Report.

Aggarwal, P. K. and Mall, R. K., 2002. Climate change and rice yields in diverse agro-environments of India. II. Effect of uncertainties in scenarios and crop models on impact assessments Climatic Change, 52, pp. 331-343.

Carter, T.R., 2007. General Guidelines on the Use of Scenario Data for Climate Impact and Adaptation Assessment, Version 2. In: Intergovernmental Panel on Climate Change, 66p.

Donatelli, M., Tubiello F.N., Peruch, U., and Rosenzweig, C., 2002. Impacts of Climate Change and Elevated $\mathrm{CO}_{2}$ on Sugar Beet Production in Northern and Central Italy. Italian Journal of Agronomy, 6, pp. 133-14.

Jalota, S.K., Buttar, G.S., Sood, Anil, G.B.S., Chahal, Ray, S.S. and Panigrahy, S., 2008. Effects of sowing date, tillage and residue management on productivity of cotton (Gossypium hirsutum L.) - wheat (Triticum aestivum L.) system in northwest India. Soil and Tillage Research, 99, pp.76-83.
Jalota, S.K., Singh, Sukhwinder, Chahal, G.B.S., Ray, S.S., Panigrahy, S., Singh, Bhupinder Singh, K.B., 2010. Soil texture, climate and management effects on plant growth, grain yield and water use by rainfed maize-wheat cropping system: field and simulation study. Agricultural Water Management, 97, pp. 83-90

Jalota, S.K., Singh, K.B., Chahal, G.B.S., Gupta, R.K., Chakraborty, Somsubhra, Sood, Anil, Ray, S.S., Panigrahy, S. (2009) Integrated effect of transplanting date, cultivar and irrigation on yield, water saving and water productivity of rice (Oryza sativa L.) in Indian Punjab: field and simulation study. Agricultural Water Management, 96, pp. 1096-1104.

Mitchell, J.F.B., T.C. Johns, M. Eagles, W.J. Ingram, and R.A. Davis, 1999: Towards the construction of climate change scenarios. Climatic Change, 41, pp. 547-581.

Krishnan, P., Swain, D.K., Chandra Bhaskar, B., Nayak, S.K. and Dash, R. N., 2007. Impact of elevated $\mathrm{CO}_{2}$ and temperature on rice yield and methods of adaptation as evaluated by crop simulation studies. Agriculture, Ecosystems and Environment, 122, pp. 233-242.

Lobell, D. B., Field, C. B., Cahill, K. N., Bonfils, C., 2006. Impacts of future climate change on California perennial crop yields: Model projections with climate and crop uncertainties. Agricultural and Forest Meteorology. 141, pp. 208-218.

Mall, R.K., Lal, M., Bhatia, V.S., Rathore, L.S., Singh, Ranjeet, 2004. Mitigating climate change impact on soybean productivity in India: a simulation study. Agricultural and Forest Meteorology, 121, pp. 113-125

Nakicenovic, N., Alcamo, J., Davis, G., de Vries, B. , Fenhann, J. , Gaffin, S., Gregory, K., Grübler, A., Jung, T.Y., Kram, T., La Rovere, E.L., Michaelis, L., Mori, S., Morita, T., Pepper, W., Pitcher, H., Price, L., Raihi, K., Roehrl, A., Rogner, H.-H., Sankovski, A., Schlesinger, M. , Shukla, P., Smith, S., Swart, R., van Rooijen, S., Victor, N., and Dadi, Z., 2000. Emissions Scenarios. A Special Report of Working Group III of the Intergovernmental Panel on Climate Change. Cambridge University Press, Cambridge, UK and New York, NY, USA, 599 pp.

Naresh Kumar, S., Aggarwal, P. K., Rani, Swaroopa, Jain, Surabhi, Saxena, Rani and Chauhan, Nitin, 2011. Impact of climate change on crop productivity in Western Ghats, coastal and north-eastern regions of India. Current Science, 101, pp. 332341.

Panigrahy, S., Upadhyay, Gargi, Ray, S. S. and Parihar, J. S., 2010. Mapping of cropping system for the Indo-gangetic plain using multi-date SPOT NDVI-VGT Data. Journal of Indian Society of Remote Sensing. 38, pp. 627-632.

Srivastava, A. K., Rajeevan, M. and Kshirsagar, S. R., 2008. Development of a High Resolution Daily Gridded Temperature Data Set (1969-2005) for the Indian Region. NCC Research Report 8, National Climate Centre, India Meteorological Department, Pune, India 411005

Stockle, C.O., Martin, S.A., Campbell, G.S., 1994. CropSyst a cropping system simulation model: water/nitrogen budgets and crop yield. Agricultural Systems, 46, pp. 335-359.

Thornton Philip, Jones, K., Peter G., Alagarswamy, Gopal, Andresen, Jeff, 2009. Spatial variation of crop yield response to 
International Archives of the Photogrammetry, Remote Sensing and Spatial Information Sciences, Volume XXXVIII-8/W20, 2011 ISPRS Bhopal 2011 Workshop, 8 November 2011, Bhopal, India

ISPRS Archives XXXVIII- 8/W20; Workshop Proceedings: Earth Observation for Terrestrial Ecosystems

climate change in East Africa. Global Environmental Change, 19, pp. 54-65.

Tubiello, F. N. and Ewert, F., 2002 Modeling the effects of elevated $\mathrm{CO} 2$ on crop growth and yield: a review. European Journal of Agronomy, 18, pp.57-74.

Tubiello, F.N., Donatelli, M., Rosenzweig, C. and Stockle, C.O., 2000. Effects of climate change and elevated $\mathrm{CO} 2$ on cropping systems: model predictions at two Italian locations. European Journal of Agronomy, 13, pp. 179-189.
Wassenaar, T., Lagacherie, P., Legros, J.-P., Rounsevell, M. D. A., 1999. Modelling wheat yield responses to soil and climate variability at the regional scale. Climate Research, 11, pp. 209220.

\section{ACKNOWLEDGEMENT}

This work was carried out under the PRACRITI programme of ISRO. Authors are grateful to Dr. Ranganath R. Navalgund, Director, Space Applications Centre and Dr. Jai Singh Parihar, Deputy Director, EPSA for their encouragement in this work. 